\title{
Assessing Land Suitability for Rainwater Harvesting Using Geospatial Techniques: A Case Study of Njoro Catchment, Kenya
}

\author{
C. W. Maina ${ }^{1}$ and J. M. Raude ${ }^{2}$ \\ ${ }^{1}$ Department of Agricultural Engineering, Egerton University, P.O. Box 536-20115, Egerton, Kenya \\ ${ }^{2}$ Soil, Water and Environmental Engineering Department, Jomo Kenyatta University of Agriculture and Technology, \\ P.O. Box 62000-00200, Nairobi, Kenya
}

Correspondence should be addressed to C. W. Maina; mainawcaroline@gmail.com

Received 13 April 2016; Revised 5 August 2016; Accepted 19 October 2016

Academic Editor: Rafael Clemente

Copyright (C) 2016 C. W. Maina and J. M. Raude. This is an open access article distributed under the Creative Commons Attribution License, which permits unrestricted use, distribution, and reproduction in any medium, provided the original work is properly cited.

\begin{abstract}
Water demand increases as population increases leading to overexploitation of water resource. Consequently, there is need for improved water resources management complemented with rain water harvesting within the catchments. This study sought to assess land suitability for surface runoff harvesting using geospatial techniques. Land use/land cover maps of the area were derived from Landsat image. Land use and soils data were used in generating curve number map of the catchment. Lineaments greatly affect the storage depending on whether runoff is for surface storage or ground water recharge purposes. As a result, ArcGIS was used in delineating the lineaments from Digital Elevation Model (DEM) of the catchment. Further, using weighted overlay the catchment was grouped into categories of restricted, not suitable, moderately suitable, suitable, or highly suitable. The study found that forest, agriculture, and built-up areas occupied about $39.42 \%, 36.32 \%$, and $1.35 \%$ of catchment area, respectively. A large part of catchment was found to have curve number range of $82-89$. About $50 \%$ of the catchment was found to fall within suitable and highly suitable categories. This implied that a great potential exists for rain water harvesting within the catchment.
\end{abstract}

\section{Introduction}

One of the vital requirements for life, economic, and social development is water [1]. Water is required by human beings, plants, and animals and for ecosystem functions. Adequate water supply is critical in the development of drinking water supplies, agricultural and industrial activities. The demand of water increases linearly as population increases. According to WWO [2], the global water consumption rate doubles in every 20 years a rate that is twice the population growth rate. As a result, optimum, efficient use and management of fresh water resources with increase in population are paramount to counter the concerns caused by the observed dwindling trends of the water resources. Further, there are many sectors facing serious water shortage. For instance, approximately over $50 \%$ of rural household and at least $25 \%$ of urban households do not have access to adequate clean water [3]. Kenya is among the water scarce countries in Africa and has also seen water storage per capita deteriorate with time to critical levels. By year 2003, the available fresh water supply was $647 \mathrm{~m}^{3}$ per capita and it was estimated that, by year 2025, per capita water availability would drop to $235 \mathrm{~m}^{3}$ as a result of population growth [4]. Water scarcity is a major concern in Kenya and urgent measures are required to arrest the situation and reverse the trend to an internationally accepted per capita consumption of $1,000 \mathrm{~m}^{3}$. As a result there is need for improved water resources management and one of the viable options is to direct more efforts in rain water harvesting within the catchments.

Priority should be given to rainwater harvesting either for surface storage or for artificial recharge since this assists in sustainable management of water resources [5]. Rainwater harvesting is the process of concentrating runoff from a large area within the catchment. The concentrated runoff can later be used in a smaller area [5] for various activities. Rain water harvesting deals with a large number of spatial data that 
can be easily handled using geospatial techniques. Remote sensing and GIS are widely being applied in the field of hydrology and water resources development [6]. In Kenya, little has been done in the use of geospatial techniques to identify sites for rain water harvesting. One area that would greatly benefit from such a study is Njoro River catchment and its environs.

Over the years, Njoro River catchment has undergone dynamic land use change leading to changes in hydrologic regimes [7]. Quantities of runoff have increased over the surface causing environmental related disasters in the form of flooding and soil erosion. However, excessive runoff is a resource that can be harnessed for use by households, agriculture, and environmental improvement. The catchment's main activity is rain fed agriculture which lately has been affected by rainfall variability leading to crops failure. Though rain water harvesting has a great potential, a major knowledge gap exists concerning the choice of the most suitable areas where harvesting can be practiced. Therefore, there is need for robust methodology that can enable water resource managers identify and map existing potentials for water harvesting.

The Njoro River catchment is approximately $150 \mathrm{~km}^{2}$. It lies between latitudes $0^{\circ} 15^{\prime} \mathrm{S}-0^{\circ} 30^{\prime} \mathrm{S}$ and longitudes $35^{\circ} 20^{\prime} \mathrm{E}-$ $36^{\circ} 05^{\prime} \mathrm{E}$. The catchment originates from the Mau Hills at an altitude of about 3060 meters above sea level (m.a.s.l.) to about 1750 m.a.s.l. at the mouth where it discharges into Lake Nakuru, a Rift valley soda lake. This area has a bimodal rainfall pattern, starting from March to May, sometimes extending to June and September to November, though recently climate variability is being experienced. According to Kundu [7], the average rainfall recorded within the catchment is $1020 \mathrm{~mm}$ per annum. The catchment is covered by loamy soils in the upper forested parts having developed from ashes and other pyroclastic rocks of volcanoes and deep well drained to moderately deep loamy sandy clays (vitric andosol). The lower reaches are composed of erosive lacustrine soils as reported by Chemelil [8].

\section{Materials and Methods}

2.1. Data Used. Landsat images and Digital Elevation Model (DEM) were downloaded from http://earthexplorer.usgs.gov/ and both had a resolution of about $30 \mathrm{~m}$. Landsat images were used to generate the land use of the catchment while the DEM was used in lineament delineation and slope generation. Soil map was first downloaded from KENSORTER website for the region. The map was georeferenced and validated using soil data from previous studies within the catchment $[7,9]$. The daily rainfall data for year 1995 to 2014 was downloaded from global weather data for SWAT (http://globalweather.tamu.edu/). This data was corrected with one collected physically for the same period of time from existing weather stations in Egerton University and Kenya Agricultural and Livestock Research Organization in Njoro. The correction was carried out by getting the regression equation between the downloaded and existing weather stations data. To check the consistency of the rainfall data, a double mass curve was used. Homogeneity of the
TABLE 1: Hydrologic soil groups.

\begin{tabular}{lcc}
\hline Group & Soil type & Characteristics \\
\hline A & Sand, loamy sand, sandy & Low runoff, high infiltration \\
B & loam & Moderate infiltration rates \\
C & Sandy clay loam & Low infiltration rates \\
D & Clay, silty clay loam, sandy & High runoff potential, very \\
& clay, silt clay & low infiltration \\
\hline
\end{tabular}

data was conducted to test for any possible errors or outliers resulting from the data measurements. For instance, as a quality control measure, any sudden change in the gradient of double mass curve was associated with inconsistency in the data, and this inconsistency was then corrected.

2.2. Data Processing Techniques. The watershed boundary was delineated in ARCGIS 9.3 spatial analyst tool. The remotely sensed data and soil maps were georeferenced and geometrically rectified. All data were projected to WGS_1984 UTM Zone 36S. To generate the land use map of the catchment, image preprocessing, that is, georeferencing and rectification, was performed in ERDAS imagine 9.2 and Arcmap 9.3. Image enhancement was carried out using the contrast stretch, histogram equalization at $\mathrm{DN}$ range of 0 255. A $3 \times 3$ filter was used to filter the image so as to sharpen the satellite image and DEM. Filtering aided in detecting the linear features like the faults, drainages, and rivers. Supervised classification in false colour composite using maximum likelihood classification was conducted. To aid in identifying distinct classes especially built-up area and grassland, false colour combination of bands 4,5 , and 3 was used. The combination was informed through use of signature separability which revealed that band 5 was the most effective band in classes' separation. Image interpretation elements, that is, tone, pattern, size, association, shape, and site, were used in land use identification. After the supervised classification, validation was undertaken.

2.3. Curve Number and Runoff. The Soil Conservation Service Curve Number (SCS-CN) method was used in estimating volume of direct surface runoff. The method was reported by Fan et al. [10] to be enduring in predicting and estimating surface runoff in ungauged rural catchment like the Njoro River catchment. Further, according to the authors, the land use/land cover parameters can easily be extracted from remotely sensed images. This data aids in catering spatial distribution of runoff generation. To calculate curve number, hydrologic soil groups (HSG), land cover type, antecedent soil moisture, and hydrologic condition factors were of paramount importance. HSG map of the catchment was generated by reclassifying the soils using information presented in Table 1. The HSG and land use layer of the catchment were converted into raster format. In ERDAS, model maker was used in matching land cover and HSG. Appropriate curve number value was assigned to each cell in the output layer. HSG is classified into 4 groups, A, B, C, and 
TABLE 2: Weightage and ranking for features.

\begin{tabular}{|c|c|c|c|c|}
\hline Layer & Weight & Feature class & Runoff generation rank & Rain water harvesting/storage site \\
\hline Lineaments & 15 & Lineaments & 1 & 1 \\
\hline \multirow{3}{*}{ Soil } & \multirow{3}{*}{28} & Loam & 1 & 1 \\
\hline & & Sandy clay loam & 2 & 2 \\
\hline & & Sandy clay & 3 & 3 \\
\hline \multirow{4}{*}{ Slope } & \multirow{4}{*}{27} & $>30 \%$ & 4 & 1 \\
\hline & & $8-30 \%$ & 3 & 2 \\
\hline & & $2-8 \%$ & 2 & 3 \\
\hline & & $0-2 \%$ & 1 & 4 \\
\hline \multirow{5}{*}{ Land use } & \multirow{5}{*}{30} & Waterbody & 1 & 1 \\
\hline & & Forest & 2 & 2 \\
\hline & & Agriculture & 3 & 3 \\
\hline & & Bare land & 4 & 4 \\
\hline & & Built-up & 5 & 1 \\
\hline
\end{tabular}

$\mathrm{D}$, and reflects the infiltration rates of soils [11]. Group A has highest infiltration and low curve number while group D has lowest infiltration and high curve number (Table 1).

In a study conducted by Raude [9] within the Njoro catchment, Kenya, on surface runoff and soil loss under varying rainfall intensity and selected land use practices, it was observed that Antecedent Moisture Content (AMC) II was useful in determining surface runoff of the catchment. These findings are based on use of a rainfall simulator to study variations from different rainfall intensities. Different measurements were taken from runoff plots and the results were compared with runoff data collected during actual rainfall events. In the same study, soil samples were collected and their moisture content was determined using the gravimetric method. Further runoff coefficients of the area were calculated and a composite runoff coefficient was determined. The results were used in understanding runoff values calculated using the SCS-CN model. As a result, this study adopted the AMCII during curve number determination. To estimate the direct runoff from storm, the rainfall runoff equation given by Balvanshi and Tiwari [12] was used. To apply this equation, it was assumed that initial abstraction of the 5-day antecedent moisture was well represented by $0.2 S$

$$
Q=\frac{(P-0.2 S)^{2}}{P+0.8 S} \quad P>0.2 S,
$$

where $S$ is watershed storage, $\mathrm{mm}$; $Q$ is actual direct runoff, $\mathrm{mm} ; P$ is total rainfall, $\mathrm{mm}$.

$S$ is related to curve number using equation (4), as given in Fan et al. [10],

$$
S=\frac{25400}{\mathrm{CN}}-254 .
$$

2.4. Lineaments Identification. Liu et al. [13] reported that DEM is useful in lineaments studies; hence, in this study DEM was used for lineament identification. Shaded relief images from DEM were created. In shaded relief images, lineaments were identifiable using variations in sun illumination. The illumination is associated with changes in aspect angle and slope gradient. Eight shaded relief images were created with light sources from eight different directions, that is, $0^{\circ}, 45^{\circ}, 90^{\circ}, 135^{\circ}, 180^{\circ}, 225^{\circ}, 270^{\circ}$, and $315^{\circ}$. The first four shaded relief images were combined into first image while the second four sets were combined into the second image as given by Abdulla et al. [14]. The lineaments were then digitized in a GIS environment. The lineaments were further buffered at $100 \mathrm{~m}$ since surface water storage was considered in selection of a suitable site.

2.5. Suitable Site. The different thematic layers were integrated in GIS environment where overlay, buffering, and weighting operations were carried out by first converting all layers to raster format. Since surface water storage was being considered, the lineaments were buffered at a distance of $100 \mathrm{~m}$ as they showed weak points where infiltration was likely to be high. Proximity of harvesting site to water bodies and roads was also buffered to a distance of $300 \mathrm{~m}$. For high efficiency runoff generation, catchment slope is usually steep. Higher slopes were considered to have positive impacts on generation of runoff but were undesirable for storage site identification. In assessing the runoff potential and rain water suitability, weighted overlay index in GIS was used. Almost the same methodology was followed by Sarup et al. [15] where potential sites for ground water recharge zones were delineated using geospatial techniques. In this study, individual thematic layers were assigned weightage and also their classes a rank depending on the influence of the parameter to rain water harvesting or their contribution to the output (Table 2). The classes with higher values indicated the most suitable sites. The final score was a product of rank and weightage where the site suitability was classified to be restricted, not suitable, moderately suitable, suitable, or highly suitable. The areas covered by each suitability category were calculated using the area tool. Further, the percentage suitability was estimated by considering each specific area and the total catchment area; that is,

$$
\frac{\text { Suitability category area }}{\text { Total area }} \times 100 \text {. }
$$




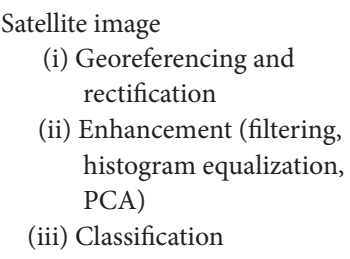

(i) Georeferencing and rectification

(ii) Enhancement (filtering, histogram equalization, PCA)

(iii) Classification
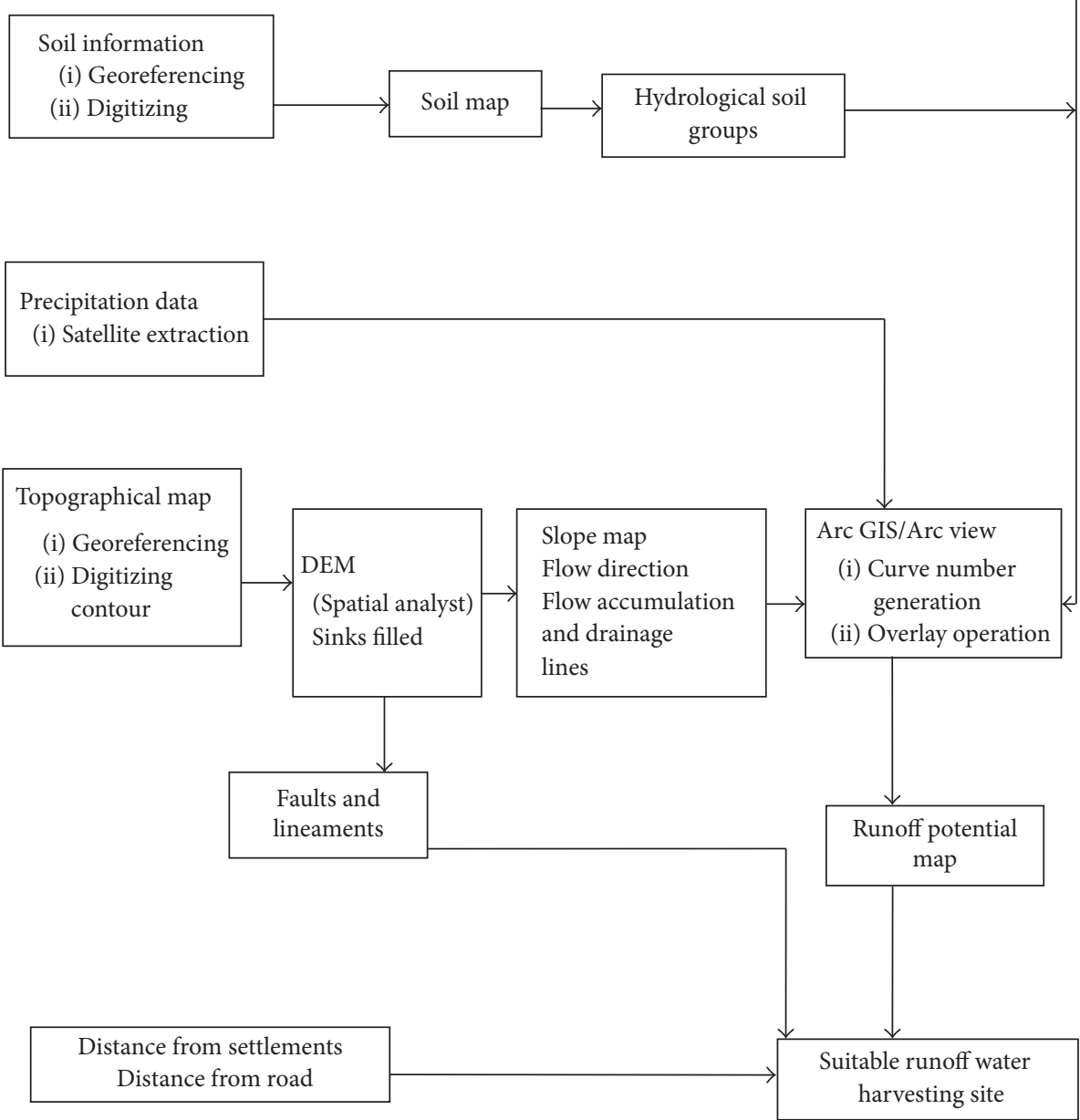

FIGURE 1: Methodology adopted for study.

Though rainfall is a key factor when assessing the suitability of a region as a harvesting site, in this study it was not weighted since it was found that rainfall was almost uniformly distributed within the study catchment. A summary of the methodology adopted is presented in Figure 1.

\section{Results and Discussion}

3.1. Land Use/Land Cover. The areas of different land uses/ land cover as calculated were found to range from $39.42 \%$ and $0.54 \%$ in forest and water body, respectively (Table 3 ). Water body was found to have the smallest area probably because river classification was difficult since water was not visible but the riparian vegetation marked river's route. The riparian vegetation could have added on the percentage of the forest available since the vegetation reflectance was close to that of forest and this was not separated. In addition, the natural forests, secondary forest, and the agro forests were not separated in this study which could be associated with the fact that forests in general have a higher percentage (Figure 2).

On the other hand, agriculture which is the main economic activity within the study area was found to occupy $36.52 \%$. Baldyga et al. [16] had reported small scale farming and cattle rearing was on the increase within the catchment. As a result, rain water harvesting within the catchment can lead to improved agriculture. 
TABLE 3: Land use/land cover areas in ha and \%.

\begin{tabular}{lcc}
\hline Land use & Area (ha) & Area (\%) \\
\hline Water body & 80.46 & 0.54 \\
Shrub & 2092.95 & 14.14 \\
Agriculture & 5404.32 & 36.52 \\
Built-up area & 198.81 & 1.35 \\
Grass land & 673.47 & 4.55 \\
Forest & 5833.62 & 39.42 \\
Bare land & 515.34 & 3.48 \\
\hline Total & $\mathbf{1 4 7 9 8 . 9 7}$ & $\mathbf{1 0 0}$ \\
\hline
\end{tabular}

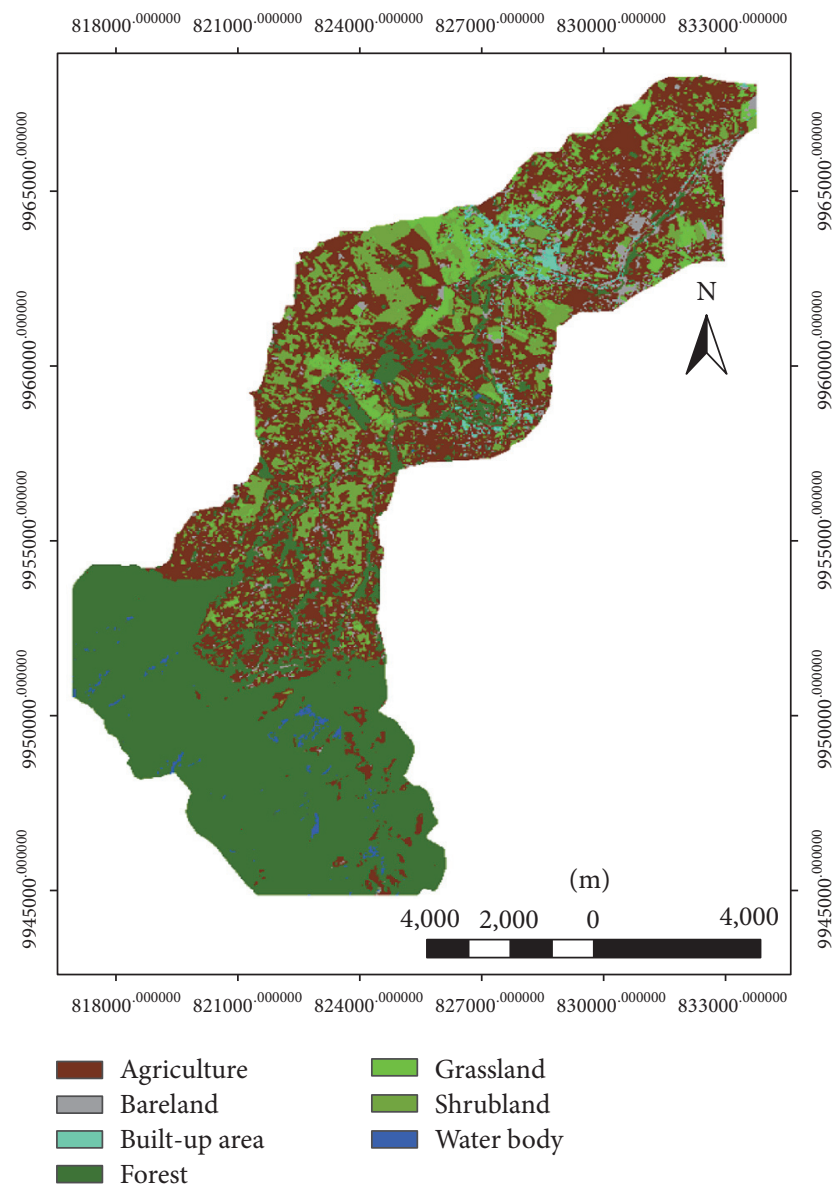

Figure 2: Land use map.

3.2. Soils. The soils within the study area were found mainly to be sandy loam, clay loam, and sandy clay loam though some sections were found to have loam soils. It was found that the hydrologic soil groups within the catchment are B, C, and D (Figure 3 ) at $15.40 \%, 37.97 \%$, and $46.63 \%$, respectively. The higher percentage of the soil was found to fall in group $\mathrm{D}$ which translated to very low infiltration and high runoff leading to high curve number. As a result, the soils within the catchment were found to be useful in surface water harvesting and generation of much runoff.

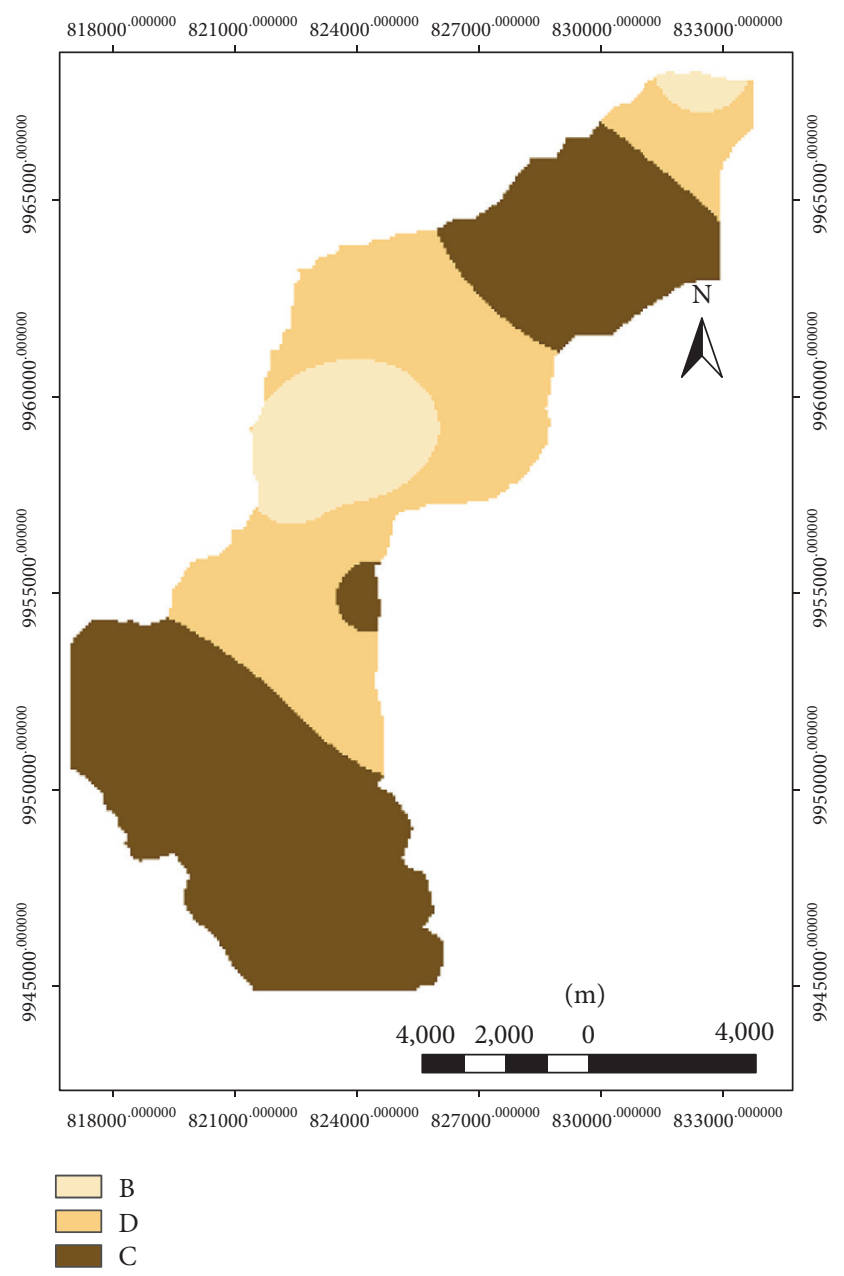

Figure 3: Hydrologic soil group map.

3.3. Curve Number. It was found that the curve numbers were all above 50 indicating that runoff potential within the catchment was high. The range of curve number was found to be between 55 and 100 (Figure 4) during normal periods. The lowest curve number was recorded in natural forest area while the highest $\mathrm{CN}$ value was within the water body. Similar results were reported by Fan et al. [10] where they estimated composite curve numbers for a catchment in Guangzhou, China. The current study found that built-up area was found to have a range of 85 to 94 depending on the soil type and percentage of impervious area available (Table 4).

The built-up area has more impervious surfaces leading to low infiltration which led to higher curve number. A curve number is used to ascertain how much rainfall infiltrates into soil and how much rainfall becomes surface runoff. The values range from 0 to 100 and they represent the ability of the land surface to capture water [1]. According to Balvanshi and Tiwari [12] low curve number indicates that water easily infiltrates into soils giving rise to less runoff while high curve number means that water is not captured by the land surface; thus, more runoff is generated. 


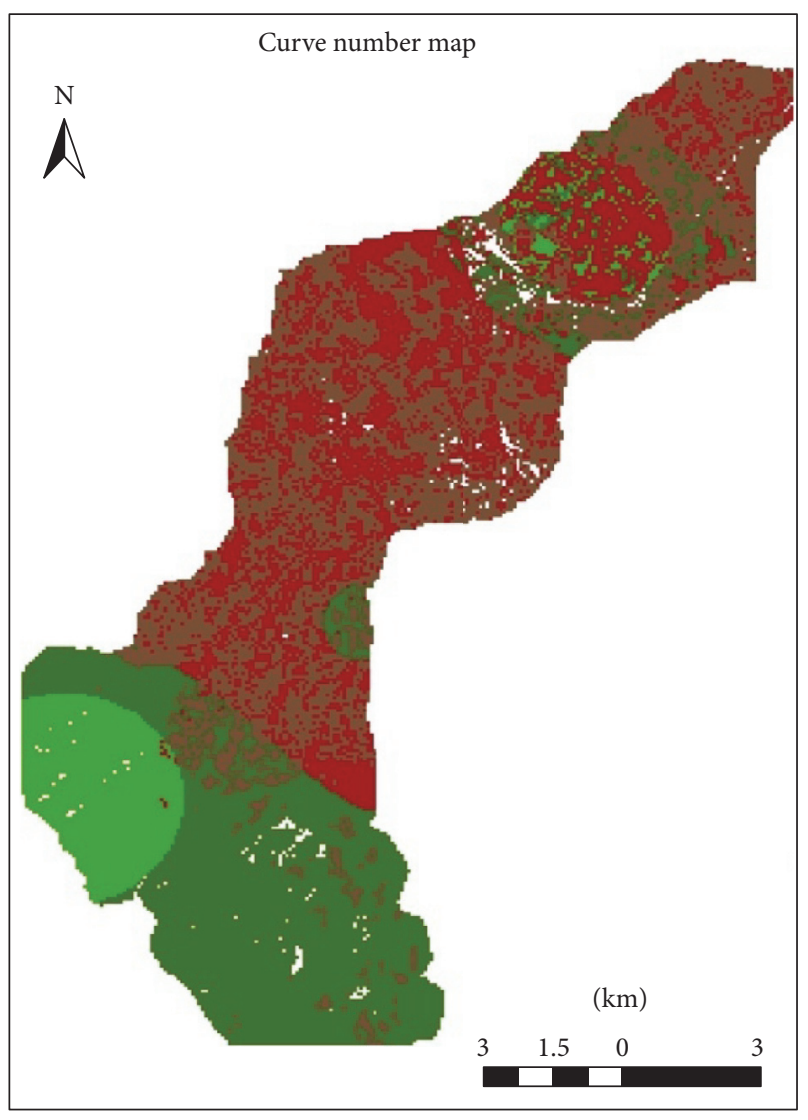

Curve number

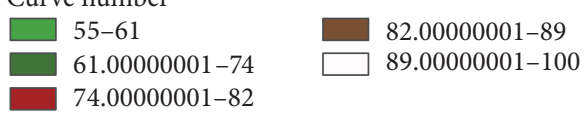

FIGURE 4: Curve number map.

TABLE 4: Curve numbers.

\begin{tabular}{lcc}
\hline CN range & Area & \% area \\
\hline $55-61$ & 1216.92 & 8.25 \\
$61-74$ & 4444.86 & 30.14 \\
$74-82$ & 3599.19 & 24.40 \\
$82-89$ & 5281.39 & 35.81 \\
$89-100$ & 205.78 & 1.40 \\
\hline Total & $\mathbf{1 4 7 4 8 . 1 4}$ & $\mathbf{1 0 0}$ \\
\hline
\end{tabular}

3.4. Runoff. It was found that for rainfall amount of $101 \mathrm{~mm}$ the runoff generated ranged between 13.22 and $83.55 \mathrm{~mm}$ where the lowest value was recorded within the forest and 83.55 was within the built areas. This was in agreement with the curve numbers earlier generated. In forested area the vegetation increases infiltration rates, interception losses, and retention which consequently decrease the volume of runoff. The built-up areas increase the impervious layers, thus reducing infiltration rate, and this leads to increase in runoff. Figures 5 and 6 represent the runoff map and the lineaments in the study area, respectively. The low runoff areas were found to be in forests which are also unsuitable for rain
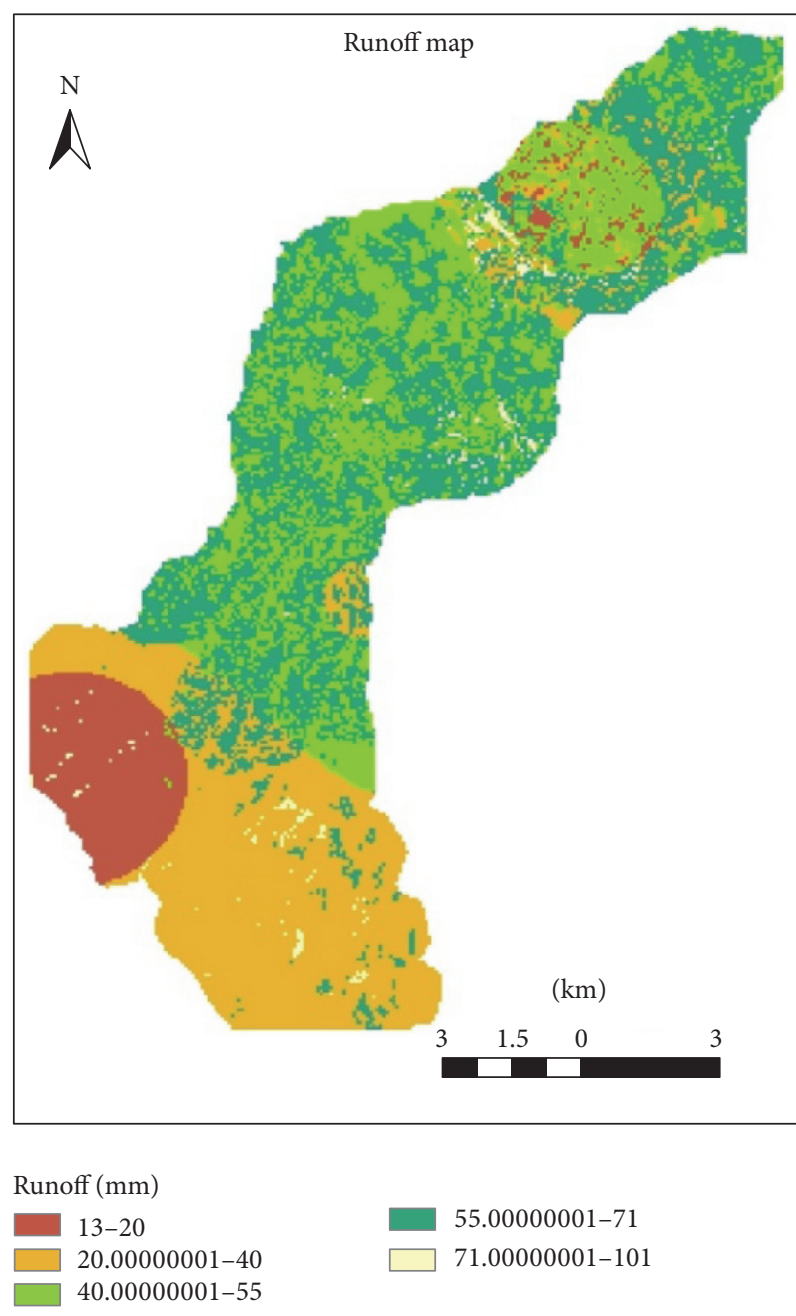

FIgURE 5: Runoff map.

water harvesting sites. It was observed that within the forest some areas generated higher amount of runoff compared to the main areas. This could have been as a result of forest encroachment or tree cutting for illegal charcoal burning rampant in the study area.

3.5. Lineaments. Lineaments were mapped to give more information on potential sites of the rainwater harvesting structures depending on whether the sites are earmarked for surface water storage or ground water recharge. In this study the lineaments were buffered since they represented spatial influence that would lead to leakage or seepage for the surface water storage. Lineaments affect surface storage, ground water recharge, and base flow and thus play a vital role in the performance efficiency of structural measures [17]. They sometimes serve as indicators of rock solubility and can be associated with fissure conduits. The lineaments indicate zones of high permeability and concentrated groundwater flow [18]. Lineaments would be highly suitable when ground water recharge is to be conducted and least suitable for surface water harvesting since they would encourage leakage or infiltration. 


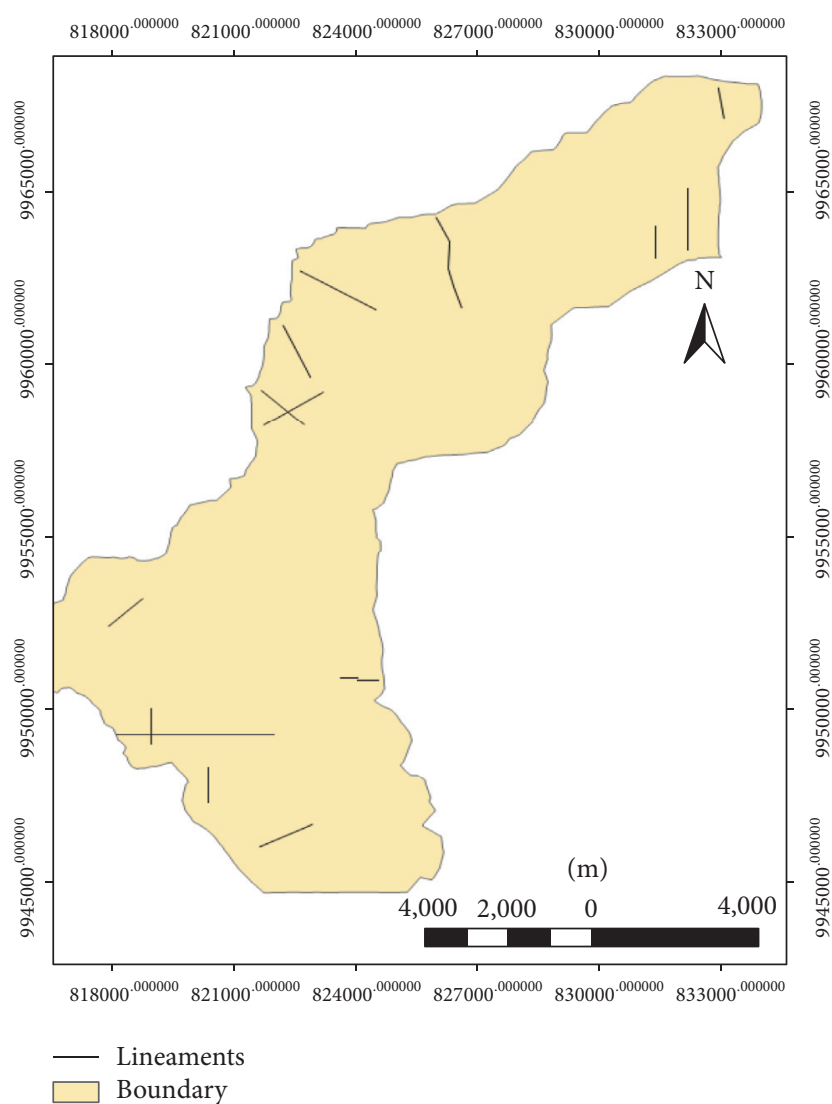

Figure 6: Lineament map of Njoro catchment.

TABLE 5: Slope classification.

\begin{tabular}{lccc}
\hline Slope & Area (ha) & $\%$ area & Description \\
\hline$>30$ & 1.40 & 0.01 & Steeply dissected to mountainous \\
$8-30 \%$ & 2619.25 & 17.76 & Rolling to hilly \\
$2-8 \%$ & 7814.11 & 52.98 & Flat to gently undulating \\
$0-2 \%$ & 4313.377 & 29.25 & Generally flat \\
\hline Total & $\mathbf{1 4 7 4 8 . 1 4}$ & $\mathbf{1 0 0}$ & \\
\hline
\end{tabular}

3.6. Slope. The highest area percentage of the catchment as presented in Table 5 was found to fall under flat to gently undulating category covering $52.98 \%$, followed by generally flat class occupying an area of $29.25 \%$.

These two slope classification categories offer favorable rain/runoff potential collection sites. Such flat areas allow water to collect and not to flow away and, therefore, naturally help in concentrating the rainfall runoff from a given storm. On the other hand, steep slopes favor runoff generation and were ranked high for runoff generation sites while for rain water harvesting flat slope was ranked higher. Further, the sites with $8 \%$ slope were considered suitable for harvesting runoff on condition that erosion control is practiced according to recommendations by Tumbo et al. [19].

3.7. Site Suitability. The degree of suitability was assessed through sensitivity analysis where weights assigned to the

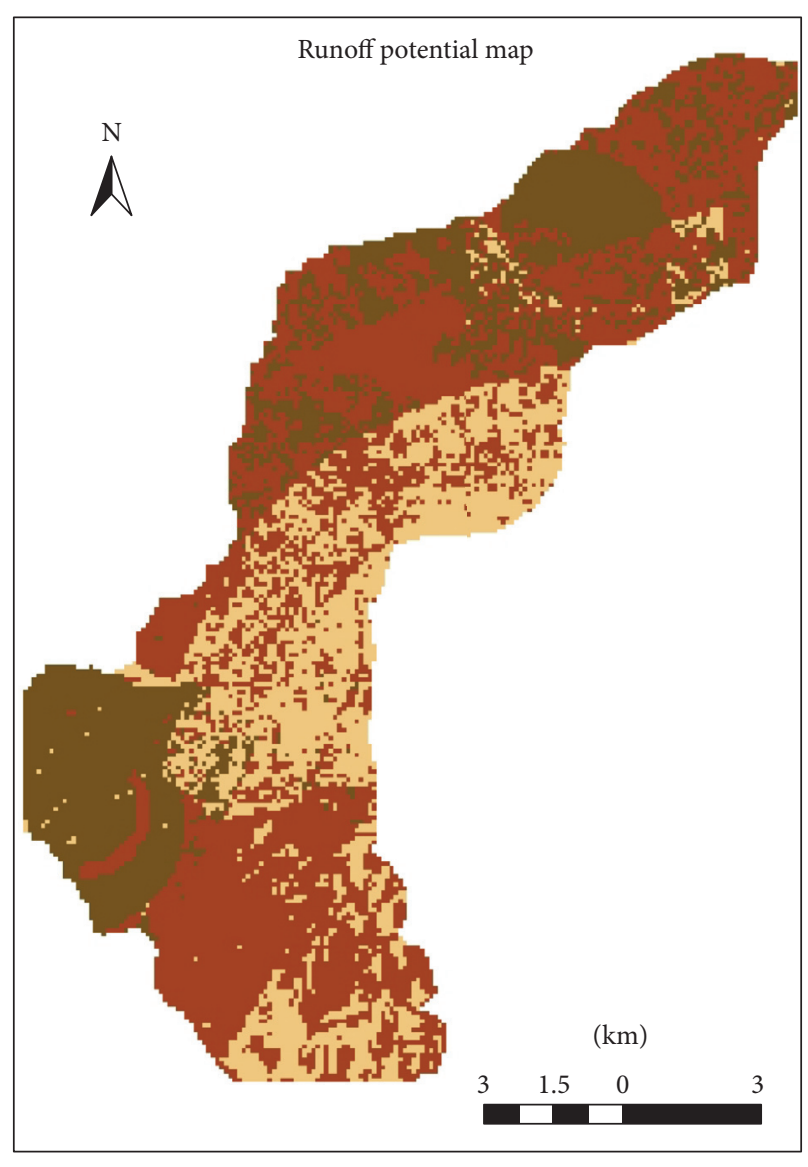

$$
\begin{aligned}
& \text { Runoff potential } \\
& \text { Low } \\
& \text { Medium } \\
& \square \text { High }
\end{aligned}
$$

FIGURE 7: Runoff potential map.

factors were varied starting with equal weight assignment. It was found that soils, land cover, and slope layers are the most sensitive layers. It was also observed that HSG $B$ areas generated less runoff meaning these areas were of low runoff potential suitability. The runoff potential of the catchment was found to be $22.67 \%, 71.61 \%$, and $5.72 \%$ for low, medium, and high potential areas, respectively, as presented in Figure 7. It was also found that low and medium runoff generation falls within forested areas. This could be as a result of high infiltration rates within the forests leading to less rainfall being converted into runoff. The high runoff potential areas are characterized by low infiltration rates in built-up areas and areas with degraded soil conditions. In addition, areas with bare rock or rock outcrops create favorable conditions for runoff generation.

Restricted area includes the forest, built-up area, water body, and riparian zones which take about $10.17 \%$ of the total catchment area. Classification of the area as restricted was based on FAO criteria. The criteria indicate that rainwater harvesting sites should not be within natural forests, protected area, or areas of ecological importance and built-up 


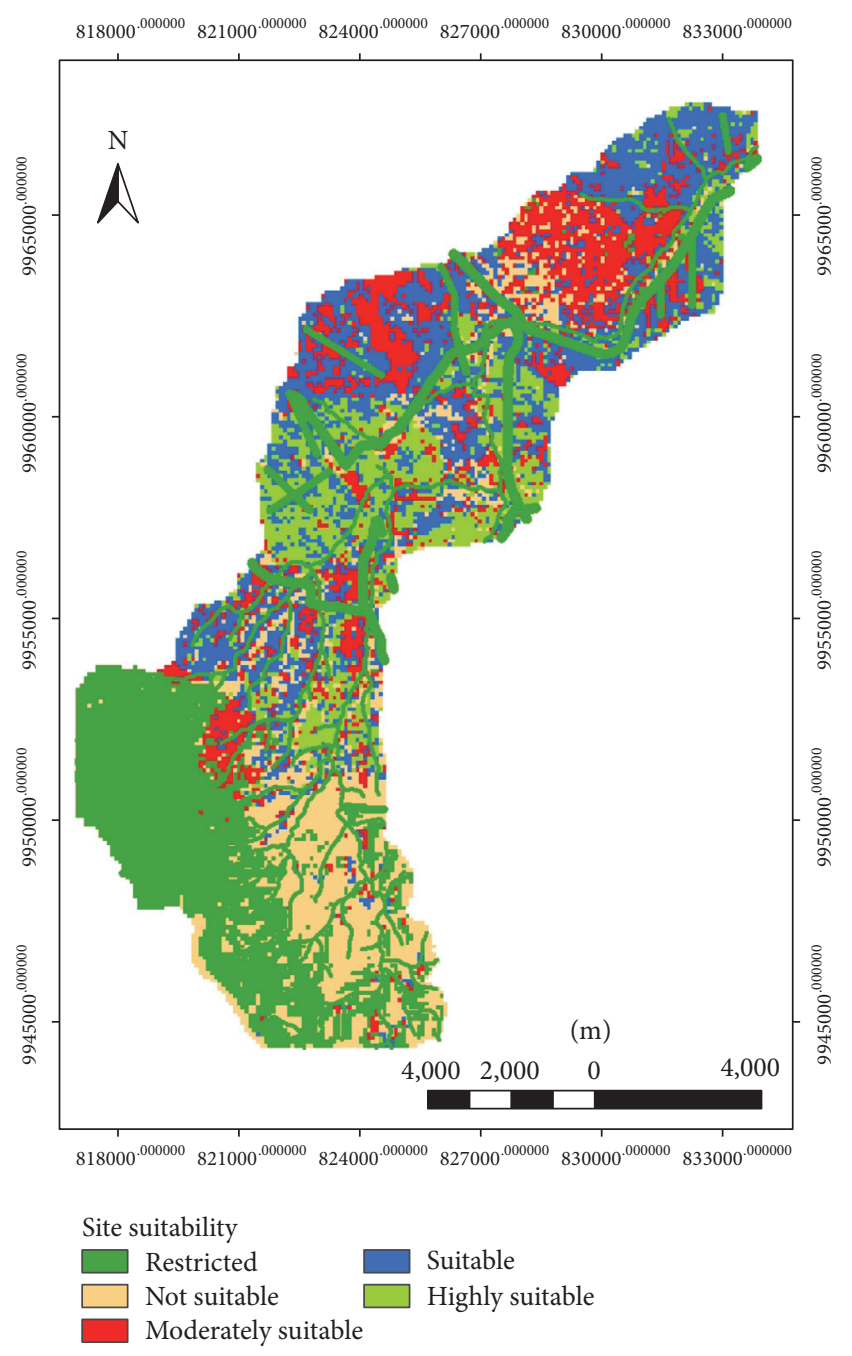

FIGURE 8: Rain water harvesting site suitability.

TABLE 6: Rain water harvesting suitability.

\begin{tabular}{lcc}
\hline Suitability & Area (ha) & Area (\%) \\
\hline Restricted & 1499.72 & 10.17 \\
Not suitable & 4255.98 & 20.86 \\
Moderately suitable & 2931.50 & 19.88 \\
Suitable & 5482.10 & 37.17 \\
Highly suitable & 578.84 & 11.92 \\
\hline Total & $\mathbf{1 4 7 4 8 . 1 4}$ & $\mathbf{1 0 0}$ \\
\hline
\end{tabular}

areas. To ensure that water harvesting sites were not within the water body river buffer was also considered, thus adding more restricted areas as shown in Figure 8. Further, areas with lineaments as presented in Figure 8 were considered since they are classified as not being suitable for surface runoff storage. It was observed that only $11.92 \%$ of the catchment area was highly suitable while the highest percentage fell in the category of suitable at $37.17 \%$ (Table 6).

Thus, it was observed that almost $50 \%$ of the catchment can be suitable for rain water harvesting. If implemented, rainwater harvesting in Njoro catchment can improve availability of water for domestic and nondomestic purposes. Also agriculture through irrigation can be improved if water harvesting is practiced other than relying on rain fed agriculture.

\section{Conclusion}

The land use/land cover within Njoro catchment was found to be mainly forest accounting for about $39.42 \%$ while agricultural area was found cover about $36.52 \%$ of the catchment area. Built-up area occupied only $1.35 \%$ of the catchment. The curve numbers within Njoro catchment range from 55 to 100. The forested area was found to have low curve number especially where hydrologic soil group B dominates, resulting in low runoff generation. Runoff generation potential within the catchment was found to be medium occupying an area of $72 \%$, an indicator of direct runoff that can be harnessed. Slopes of the catchment were found to range from 0 to $35 \%$ since in runoff potential mapping steep slope is favorable, while for harvesting sites the flat slope is more favorable. DEM proved useful in lineament delineation since it was not possible to delineate the lineaments from Landsat imagery because the area has been cultivated. Also, the catchment has different other land uses that could not allow identification of lineaments. Sensitivity analysis conducted during weighting of layers for suitable rainwater harvesting sites selection showed that land use, soils, and slope are the key parameters that affect the process. Almost 50\% catchment's area was found to be suitable for rain water harvesting. This is a good indicator that availability of water can be improved if the proposed technology was adopted. Though different rain water harvesting techniques have specific requirements, in this study, a general criterion has been used. Further studies can be conducted to narrow down different rainwater harvesting techniques that can be used to identify the most suitable technique for the study area. In addition, the study can further be improved by incorporating the social component where public needs and preference are assessed.

\section{Competing Interests}

The authors declare that they have no competing interests.

\section{References}

[1] D. Ramakrishnan, A. Bandyopadhyay, and K. N. Kusuma, "SCS$\mathrm{CN}$ and GIS-based approach for identifying potential water harvesting sites in the Kali Watershed, Mahi River Basin, India," Journal of Earth System Science, vol. 118, no. 4, pp. 355-368, 2009.

[2] WWO (World Water Organization), "Water Facts \& Water Stories from Across the Globe," 2010, http://www.theworldwater .org/water_facts.php.

[3] WHO, Copying with Water Scarcity. A Strategic Issue and Priority for System-Wide Action, 2006, http://www.unwater.org/ downloads/waterscarcity.pdf.

[4] S. R. Ariyabandu, "Very low cost domestic roof water harvesting in humid tropics, Its role in water policy," DFID Kar Contract R7833 Report R4, 2003. 
[5] M. Bakir and Z. Xingnan, "GIS and Remote Sensing applications for rain water harvesting in the Syrian Desert (Al-Badia)," in Proceedings of the 12th International Water Technology Conference (IWTC '12), Alexandria, Egypt, March 2008.

[6] M. P. Sharma and A. Kujur, "Applications of remote sensing and GIS for ground water recharge zone in and around Gola block, Ramgargh district, Jharkhand, India," International Journal of Science and Research Publication, vol. 2, no. 2, pp. 1-14, 2012.

[7] P. M. Kundu, An evaluation of the impact of land use and land cover change on stream flows in river Njoro catchment using remote sensing and Geographical Information System techniques [Ph.D. thesis], Department of Agricultural Engineering, Egerton University, Njoro, Kenya, 2007.

[8] M. C. Chemelil, The effect of human induced watershed changes on stream flow [Ph.D. thesis], Loughborough University, Loughborough, UK, 1995.

[9] J. M. Raude, Assessing surface runoff and soil loss under varying rainfall intensity under selected landuse in Njoro catchment [M.S. thesis], Egerton University, 2006.

[10] F. Fan, Y. Deng, X. Hu, and Q. Weng, "Estimating composite curve number using an improved SCS-CN method with remotely sensed variables in Guangzhou, China," Remote Sensing, vol. 5, no. 3, pp. 1425-1438, 2013.

[11] V. T. Chow, D. K. Maidment, and L. W. Mays, Applied Hydrology, McGraw-Hill Book Company, New York, NY, USA, 2002.

[12] A. Balvanshi and H. L. Tiwari, "A comprehensive review of runoff estimation by the curve number method," International Journal of Innovative Research in Science Engineering and Technology, vol. 3, no. 11, pp. 17480-17485, 2014.

[13] T. Liu, H. Yan, and L. Zhai, "Extracting relevant features from DEM for ground water potential mapping," The International Archives of the Photogrammetry, Remote Sensing and Spatial Information Science, vol. 15, no. 7, pp. 113-119, 2015.

[14] A. Abdulla, J. M. Akhr, and I. Abdullah, "Automatic mapping of lineaments using shaded relief images derived from DEMs in the Maran-Sungi Lembing Areas, Malysia," Bund Journal, vol. 15, pp. 949-957, 2010.

[15] J. Sarup, M. K. Tiwari, and V. Khatediya, "Delineating ground water prospects zones and identification of artificial recharge sites using Geospatial techniques," International Journal of Advanced Technology and Engineering Research, vol. 1, no. 1, pp. 6-20, 2011.

[16] T. J. Baldyga, S. N. Miller, W. Shivoga, and M. Gichaba, "Assessing the impact of land cover change in Kenya using remote sensing and hydrologic modelling," in Proceedings of the ASPRS Annual Conference, Denver, Colo, USA, May 2004.

[17] K. M. Mayilvaganan, P. Mohana, and K. B. Naidu, "Delineating ground water potential zones in Thurinjapuram watershed using geospatial techniques," Indian Journal of Science and Technology, vol. 4, no. 11, pp. 1470-1476, 2011.

[18] J. N. Bruning, A Digital Processing Data Compilation Approach for Using Remotely Sensed Imagery to Identify Geological Lineaments in Hard-Rock Terrains: An Application for Groundwater Exploration in Nicaragua, Department of Geological/Mining Engineering \& Sciences, Michigan Technological University, Houghton, Mich, USA, 2008.

[19] S. D. Tumbo, B. P. Mbilinyi, H. F. Mahoo, and F. O. Mkilamwinyi, "Identification of suitable indices for identification of potential sites for rainwater harvesting," Tanzania Journal of Agricultural Sciences, vol. 12, no. 2, pp. 35-46, 2014. 

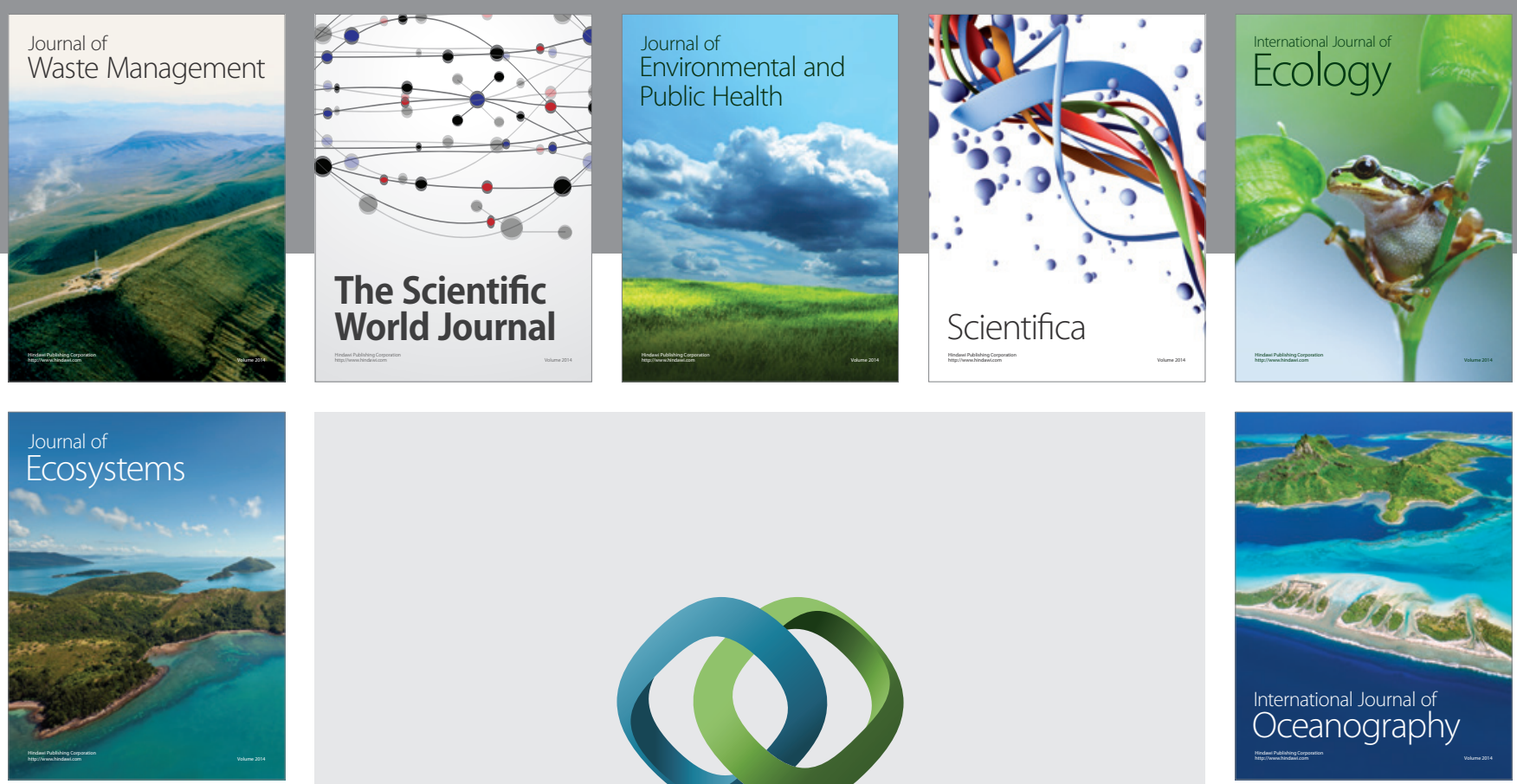

The Scientific World Journal
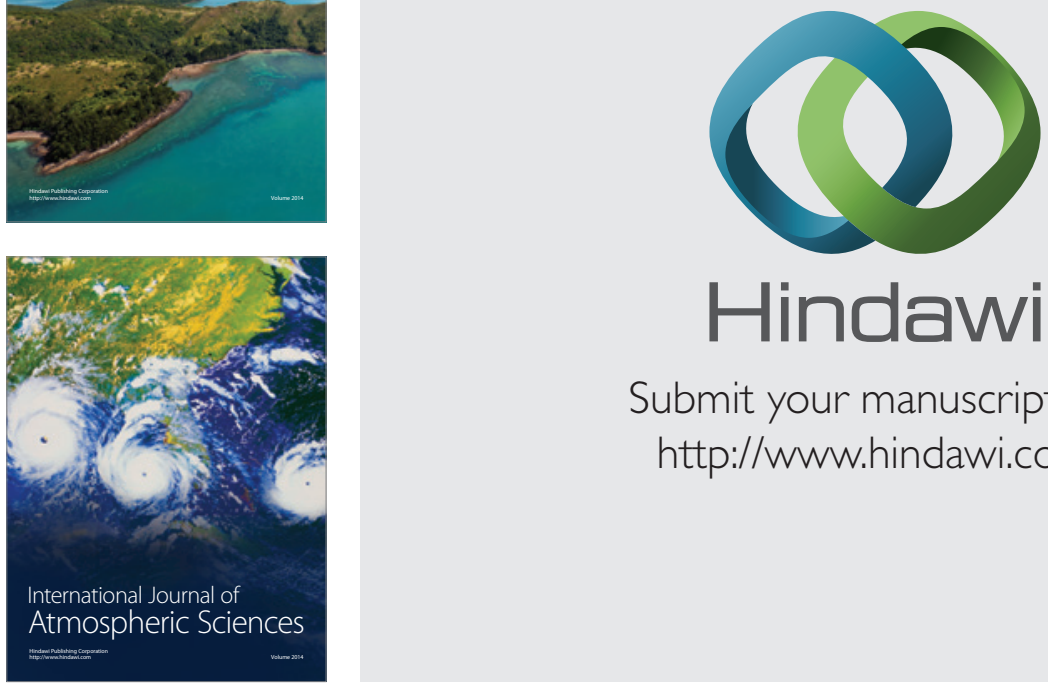

\section{Hindawi}

Submit your manuscripts at

http://www.hindawi.com
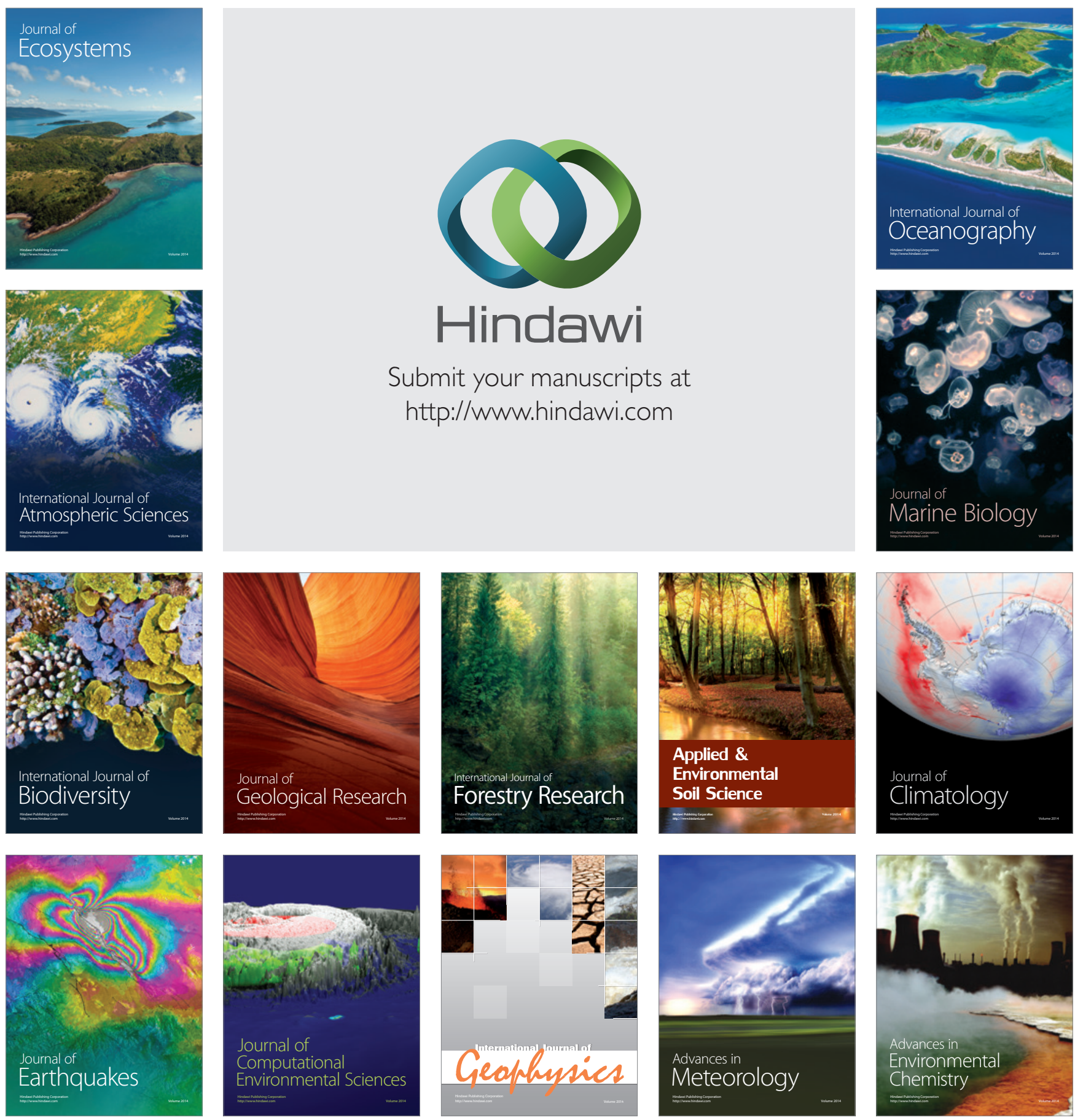